\title{
O luto perinatal e neonatal e a atuação da psicologia nesse contexto
}

\author{
Neonatal grief and the role of psychology in this context \\ El luto neonatal y el papel de la psicología en este contexto
}

\section{Resumo}

Atualmente, a morte na infância é pouco comum, considerando-se todos os recursos de modernidade que se disponibilizam hoje, quais sejam, cuidado pré-natal, UTI neonatal, dentre outros. Por isso mesmo, quando acometida por essa fatalidade, a família sente estranheza e forte impacto. A perda de um bebê pode produzir uma dor intolerável, uma vez que significa frustração de desejos, fantasias, devaneios e não menos importante, a impotência ante a possibilidade de aplicar sua capacidade de ser mãe/pai. Neste sentido, salienta-se a necessidade de profissionais como o psicólogo, a fim de que possa auxiliar a família a enfrentar o luto parental e a elaboração da perda de um filho. Desta forma, este estudo visou dissertar sobre a importância da intervenção psicológica em situações de luto: perinatal e neonatal. A partir de uma pesquisa qualitativa, de revisão bibliográfica, foi possível identificar que esse tipo de luto contraria o que culturalmente em nossa sociedade se espera sobre o andamento do ciclo de vida. Isso posto, diante do que essas perdas podem provocar nas famílias e até mesmo nas equipes de saúde, faz-se necessária a presença do psicólogo nesse contexto. Consubstancialmente, salienta-se a importância de estudos futuros que possam investir em novas reflexões acerca do luto perinatal, uma vez que as considerações trazidas por eles podem ter implicações na prática do psicólogo no âmbito hospitalar.

Palavras-chave: Luto; Neonatal; Perda; Parentalidade; Perinatal.

\begin{abstract}
Currently, death in childhood is uncommon, considering all the modern resources that are available today, namely, prenatal care, neonatal ICU, among others. For this reason, when affected by this fatality, the family feels strangeness and strong impact. The loss of a baby can produce intolerable pain, since it means frustration of desires, fantasies, daydreams and not least, the impotence before the possibility of applying your ability to be a mother / father. In this sense, the need for professionals such as the psychologist is emphasized, in order to help the family to cope with parental mourning and the elaboration of the loss of a child. Thus, this study aimed to talk about the importance of psychological intervention in grieving situations: perinatal and neonatal. From a qualitative research, from a bibliographic review, it was possible to identify that this type of mourning goes against what is culturally expected in our society about the life cycle. That said, in view of what these losses can cause in families and even in health teams, the presence of the psychologist in this context is necessary. Consubstantially, the importance of future studies that may invest in new reflections on perinatal mourning is emphasized, since the considerations brought by them may have implications for the psychologist's practice in the hospital environment.
\end{abstract}

Keywords: Mourning; Neonatal; Loss; Parenting; Perinatal.

\section{Resumen}

Actualmente, la muerte en la infancia es poco común, considerando todos los recursos modernos que se encuentran disponibles en la actualidad, a saber, atención prenatal, UCI neonatal, entre otros. Por eso, cuando se ve afectada por esta fatalidad, la familia siente extrañeza y fuerte impacto. La pérdida de un bebé puede producir un dolor intolerable, ya que significa frustración de deseos, fantasías, ensoñaciones y no menos importante, la impotencia ante la posibilidad de aplicar tu capacidad de ser madre / padre. En este sentido, se enfatiza la necesidad de profesionales 
como el psicólogo, con el fin de ayudar a la familia a hacer frente al duelo parental y la elaboración de la pérdida de un hijo. Así, este estudio tuvo como objetivo hablar sobre la importancia de la intervención psicológica en situaciones de duelo: perinatal y neonatal. A partir de una investigación cualitativa, de una revisión bibliográfica, se pudo identificar que este tipo de duelo contradice lo que se espera culturalmente en nuestra sociedad sobre el avance del ciclo de vida. Dicho esto, ante lo que estas pérdidas pueden ocasionar en las familias e incluso en los equipos de salud, es necesaria la presencia del psicólogo en este contexto. De manera consustancial, se enfatiza la importancia de futuros estudios que puedan invertir en nuevas reflexiones sobre el duelo perinatal, ya que las consideraciones que aportan pueden tener implicaciones para la práctica del psicólogo en el ámbito hospitalario.

Palabras clave: Luto; Neonatal; Pérdida; Crianza de los hijos; Perinatal.

\section{Introdução}

A relação que se constitui entre as mães e seus filhos, ainda que no ventre, pode ser considerada um dos elementos fundamentais do psiquismo humano, uma vez que muitas vezes é a partir desta relação que a criança pode aprender o mundo a sua volta. Badinter (1985) afirma que para o senso comum, a maternidade surge na vida da mulher como um instinto, uma vocação: através deles é possível amar incondicionalmente um filho. Segundo ela, esse é um assunto polêmico, uma vez que o que muitos autores apontam como instinto materno, não passa de uma construção sociopolítica passível de mudar de tempos em tempos.

Da mesma forma para Dolto (1984) o sentimento materno foi considerado como fruto de uma construção estabelecida no início da vida entre jovens meninas e suas mulheres de referência, bem como do seu processo emocional frente à castração. Entretanto, Badinter (19885) afirma que passa-se a observar isso apenas a partir do século XIX, visto que até o XVIII o percurso histórico da relação entre mães e filhos evidencia uma relação fria e indiferente (Badinter, 1985). Dolto (1984) por sua vez, afirma que o desinteresse pela criança era uma estratégia de defesa ante o sofrimento de perder um filho, o que até o século XVIII era muito comum, visto os altos índices de mortalidade infantil. Ela afirma que se a mãe se apegasse com intensidade a seus bebês, assim como vemos hoje, certamente morreria de dor.

Lebovici (2004) ao dissertar sobre a relação pai-filho, afirma que a construção da paternidade também decorre das identificações com outras figuras masculinas e com suas vivências como filhos que foram. Quintans (2018) aponta que ao serem pais, assim como as mulheres ao serem mães, vivenciam uma experiência de grande relevância para a formação da personalidade: a da parentalidade; eles não apenas são pais e tem filhos, mas sim, ganham a oportunidade de refletir sobre sua descendência. Sobre pais e mães no papel da parentalidade, Maldonado (1987) enfatiza que o nascimento de um filho é uma experiência familiar e que, muito embora infelizmente a literatura concentre-se nas mudanças psicológicas e físicas decorrentes do ciclo gravídico-puerperal apenas na mulher, é de suma relevância atentar para o fato de que a paternidade também é uma transição e da mesma forma, passível de sofrimentos, como o luto.

Bleichmar (1994) afirma que a chegada de um bebê pressupõe sua espera: tecem-se fantasias, identificações, imaginações e constroem-se cenários para recebê-lo. Quando um casal engravida, ele se imagina cuidando do bebê, como vai ser sua atuação como pai ou mãe, como esperam que o bebê vai ser, qual o futuro que espera pra ele, ou seja, a relação paisfilhos começa antes de o bebê nascer. Diferente do que ocorria há três séculos atrás, a morte na infância é pouco comum, considerando-se todos os recursos de modernidade que se disponibilizam hoje, quais sejam, pré-natal, UTI neonatal, dentre outros. Por isso mesmo, quando acometida por essa fatalidade, a família sente estranheza e forte impacto. Iaconelli (2007) afirma que a morte de um filho inverte a ordem de perdas pressupostas por todos, ao que Mercer (2002) reitera que tal acontecimento pode agravar os efeitos do luto sobre a família e o imaginário sobre possíveis filhos futuros.

A morte de uma criança pode produzir uma dor intolerável, uma vez que significa frustração de desejos, fantasias, devaneios e não menos importante, a impotência ante a possibilidade de aplicar sua capacidade de ser mãe/pai (Soifer (1992). 
Para ela, a perda de um filho trata-se de uma profunda ferida narcísica, de lenta, dolorosa e difícil recuperação. Outrossim, os pais vivenciam intenso sentimento de fracasso, inferioridade e incapacidade (Chiattone, 2007).

É importante destacar que são muitas as perdas que os pais podem enfrentar dentro do contexto da parentalidade: abortos, natimortos, óbitos neonatais precoces e tardios. Entende-se como óbito fetal, o que acontece entre a vigésima segunda semana completa de gestação, até cento e cinquenta e quatro dias anteriores ao nascimento do bebê. Inclui-se nesse contexto os óbitos de fetos com peso igual ou superior a meio quilo ou estatura a partir de vinte e cinco centímetros (Ripsa, 2008;). Classificam-se como óbitos perinatais, os que acontecem no período da vigésima oitava semana de gestação até sétimo dia após o nascimento (Caderno de Saúde Pública, 2004). Já nos óbitos neonatais, o bebê possui até seis dias de vida - óbito neonatal precoce - ou entre sete e vinte e sete dias de vida - óbito neonatal tardio. (Ministério da Saúde, 2009).

A natimortalidade, embora considerado um desfecho desfavorável e inesperado no contexto da saúde materno-infantil, ainda é menos estudada que a neomortalidade, talvez pelos poucos registros que existem a respeito. Segundo dados da Unicef, em 2018, 2,5 milhões de recém nascidos morreram nos primeiros trinta dias de vida, sendo que 1/3 deles foi no primeiro dia. Os dados apontam que grande parte desses bebês faleceu de causas evitáveis, como infecções, complicações no parto e partos prematuros (Unicef, 2019).

Em todo o mundo, a partir de uma análise feita em 184 países, classificados em quatro grupos de renda, destacam-se os que há as melhores chances para os recém-nascidos - Japão, Finlândia, Estônia, Finlândia, Cingapura, Luxemburgo - bem como, onde há as menores - Guiné-Bissau, Sudão do Sul, Costa do Marfim, Africana, Afeganistão, Somália. O Brasil, listado como país de renda média alta, alcançou o $28^{\circ}$ pior resultado, assim como o México, com 7,8 mortes neonatais a cada mil nascimentos (Unicef, 2019).

Ainda que se invistam em recursos para evitar a mortalidade perinatal e neonatal, todos os pais e mães não estão livres de passar por esta perda. Sabe-se que este evento é demasiado significante e diante disso, Kübler-Ross (1998) foi pioneira na sistematização do processo de luto e perda em estágios definidos como: negação e isolamento, raiva, barganha, depressão e aceitação. Assim sendo, aquele que vivencia o luto carece de atenção de pessoas capacitadas, tanto no âmbito hospitalar, quanto fora dele. Neste sentido, salienta-se a necessidade de profissionais como o psicólogo, a fim de que possam auxiliar a família a enfrentar o luto parental e a elaboração da perda de um filho. Outrossim, o objetivo do presente estudo é dissertar sobre a importância da intervenção psicológica em situações de luto: perinatal e neonatal.

\section{Metodologia}

Este trabalho foi elaborado a partir do método qualitativo, que se caracteriza pela busca de significados dos fenômenos humanos, tendo como próprio campo de observação o ambiente dos sujeitos, e o pesquisador como parte do instrumento de pesquisa. (Turato, 2003). Optou-se pela revisão narrativa da literatura, a fim de que se pudesse descrever e discutir o desenvolvimento do estado da arte, baseados em um ponto de vista teórico.

A análise foi feita em sua totalidade em livros e artigos obtidos com o levantamento bibliográfico no Google Acadêmico e Scielo, das quais foi possível extrair materiais nacionais e interacionais. Entretanto, apenas materiais nacionais foram utilizados. A pergunta norteadora do estudo foi "Como se dá a atuação do psicólogo em situações de óbito perinatal e neonatal"; os descritores utilizados nas duas plataformas foram os do DECs (Descritores em Ciência da Saúde), com o booleano AND (E) para realizar os cruzamentos entre: Luto; Neonatal; Perda; Parentalidade; Perinatal.

Os resultados foram interpretados e discutidos nas seguintes categorias: o luto neonatal e perinatal, a comunicação de más notícias e o trabalho em equipe e a atuação da psicologia: técnicas e procedimentos. 


\section{Resultados e Discussão}

\section{O luto neonatal e perinatal, a comunicação de más notícias e o trabalho em equipe}

Desde o início dos tempos a morte é considerada um grande mistério, consequentemente sendo vista como um tabu. A sociedade ocidental a resolve como um tema interditado e profissionais são vistos como fracassados diante da ocorrência da perda. A morte é um tema nunca desvendado pelo homem, tornando-se assunto censurado e enfrentado de forma deletéria por não a conhecermos. Dessa forma é ausente no dia a dia do mundo familiar, sendo assim transferida para os hospitais. Devemos compreendê-la como fase da vida, respeitando um momento de sofrimento, dor e perda para que isso auxilie na elaboração do luto (Costa \& Lima, 2005).

Segundo Muza et. al (2011) apud Lemes, Oliveira, Santos, Silva, \& Fitaroni (2018), a expressão do luto é vivenciada para cada pessoa de diversas formas diferentes, sendo um momento muito doloroso para os pais. O falecimento de alguém, gerando o luto, remete à sentimentos de dor e pesar, engendrando tristeza profunda e consternação familiar. Segundo Ferreira (1998) apud Lemes et al. (2018), o processo psicológico que mobiliza esforços para lidar com o pesar que a perda do objeto amado gerou, e para reorganizar o mundo interno e externo agora sem a presença física, é definido como Mourning, em inglês. O luto é visto como uma vivência com exigência de ressignificação, entendido como uma compreensão particular do indivíduo e suas capacidades nesse processo, assim como um movimento frente às perdas significativas. $O$ enlutado não apenas perde um ente querido, porém também as formas de ver o mundo à sua volta (Freitas, 2013 apud Lemes et al., 2018).

Freitas (2000) apud Lemes et al. (2018) refere que enlutar-se é um ensejo de transformação e representação, que todo mundo, em algum momento de sua vida, irá experimentar. A pessoa se sente desprotegida durante o luto; como um evento estressor, implica em uma perda, que gera o temor e a dor no indivíduo, ou na família que o vivencia. Inúmeros sentimentos podem suceder ao pensamento no decorrer da situação explicitada, como sofrimento instável, o medo, desamparo e a culpabilização.

A perda neonatal ou perinatal é uma experiência indescritível para os pais, considerando que os bebês representam o início da vida e não o fim. A elaboração do luto inicia-se após a perda, e com isso, consequentemente o indivíduo que está passando por isso vivencia sentimentos de vazio interior, irritabilidade, medo de uma nova gravidez (risco de perder outra criança), raiva, apatia, entre outros. (Alves \& Celestino, 2020). E por ser, como supracitado, um evento estressor, pode desenvolver em algumas mães transtornos psicológicos, influenciando na próxima gravidez e no relacionamento que venha a ser criado com o bebê seguinte (Hutti, 2005; Badenhorst \& Hughes, 2007 apud Montero et al. 2011).

Em uma situação de morte perinatal evidencia-se a desconsideração existente da população que experiencia o luto materno. Além disso, os responsáveis por receber e acolher essas famílias interpretam a perda como um insucesso da medicina, não estando preparados para lidar com o sofrimento familiar, e desse modo demonstram desamparo social diante dessas famílias (Muza et al., 2011 apud Lemes et al. 2018).

O luto perinatal, segundo Iaconelli (2007), é vivenciado pela sociedade como algo que deve ser evitado. Por conseguinte, as pessoas agem com negação e racionalização, e assim não entram em contato com a angústia. Na perda desse “objeto" existe algo que não é perceptível, como Freud (1976) apud Muza, Souza, Arrais, \& Iaconelli, 2013 refere que o que foi perdido no objeto e com o objeto não é vislumbrado. O contexto que envolve a morte perinatal é constituído por temas negados e com poucos focos de estudo, destarte merece uma atenção especial, posto que se trata de uma perda não plenamente reconhecida, tampouco socialmente validada (Gesteira et al., 2006 apud Muza et al., 2013).

Os óbitos neonatais estão intimamente vinculados às condições de vida e saúde da mulher, dependendo principalmente da assistência prestada durante a gestação, parto, pós-parto e sobre os cuidados imediatos prestados ao recémnascido (Fréu et al., 2008; Soares \& Menezes, 2010 apud Gaíva, Bittencourt, \& Fujimori, 2013). Isto posto, evidencia-se a 
importância da preparação por parte dos profissionais da saúde para receber e cuidar das famílias, e a necessidade de compreenderem as reações e comportamentos que eles manifestam diante da morte, para assim, ocorrer a assistência naquilo que precisam durante o processo de perda. A dificuldade em apoiar e confortar a família é explícita quando o profissional esta despreparado frente às necessidades reais da família que está no processo de luto. Por isso a importância também do envolvimento emocional com a família, pois este envolvimento servirá para promover empatia, e também permitirá que o profissional conheça seu paciente, atendendo as necessidades sem prejudicar sua atuação (Costa \& Lima, 2005; Lunardi, Sulzbach, Nunes, \& Lunardi, 2001 apud Costa \& Lima, 2005).

É importante mencionar que, ao se comportarem inadequadamente, os profissionais podem imprimir marcas importantes na família enlutada. Os pais podem lembrar das atitudes, comportamentos e comentários inapropriados até anos depois da perda do recém-nascido, colocando-os em risco de experienciarem um luto complicado. Isto posto, salienta-se que todos os momentos verbais e não verbais farão diferença positiva ou negativa na vida daquela família, sendo necessário um cuidado realizado de forma sistemática e sensível (Simwaka, Kok, \& Chilemba, 2014; Scarton et al., 2013 apud Ichikawa et al., 2017). Como relata Iaconelli (2007), algumas frases enunciadas para as mães, como "Calma, você é jovem e poderá ter outros filhos", "Foi melhor assim...", trazem repercussões consideráveis àquelas que não vivenciaram essa perda de forma mais saudável.

Por isso, há a necessidade de a equipe ser treinada nos princípios básicos de cuidados paliativos pediátricos, considerando uma comunicação efetiva, empática e fornecendo um cuidado consistente e de alta qualidade no fim de vida do recém-nascido. Educar os profissionais da saúde para enfrentamento do luto auxilia na redução dos efeitos na família advindos do processo de luto (Jonas-Simpson, Pilkington, Macdonald \& MacMahon, 2013 apud Ichikawa et al., 2017). Assim, torna-se essencial a escuta dos profissionais neonatais que assistem as famílias, para que possam compreender o processo de cuidar no final de vida, conhecer como ocorrem as relações, interações, preferências e significados elaborados.

Em relação aos Programas de cuidados paliativos citados anteriormente, são disponibilizados para recém-nascidos e suas famílias, independentemente do tempo e diagnóstico e são requisitados por instituições de assistência à essa população. O cuidado proposto nos programas, baseia-se: na oferta de apoio físico e emocional no momento da morte; na comunicação clara, consistente e com compaixão; e naa viabilização da tomada de decisão compartilhada e acompanhamento da família durante o processo de luto (Wool, 2013 apud Ichikawa et al., 2017).

Pesquisas evidenciam a importância do desenvolvimento e implementação de programas que sugerem a elaboração de protocolos como este, proporcionando acolhimento à família desde o nascimento até a morte, bem como orientações aos profissionais sobre a melhor e mais respeitosa forma de manusear o recém-nascido (Brooten et al., 2013; Mancini, Kelly, \& Bluebond-Langner, 2013 apud Ichikawa et al., 2017). É preciso humanizar todo o processo de parto, respeitando as decisões da mulher e do seu parceiro quanto à intimidade, acompanhamento e plano de parto, e diminuindo as intervenções desnecessárias (Montero et al., 2011, Sánchez et al., 2009, Taylor \& Bogdan, 1998 apud Montero et al., 2011)

No decorrer do processo de perda perinatal, todos os profissionais ficam envolvidos, explicitando o caráter multidisciplinar implícito nesse tipo de fenômeno e a importância de uma equipe preparada para o cuidado e atendimento das famílias (Montero et al., 2011). Sendo o processo de luto vivenciado de forma diferente para cada pessoa, em algumas famílias é necessário um tempo para assimilar que o bebê recém-nascido está morrendo ou morreu. Em função do estresse e ansiedade, a absorção de notícias pode ocorrer de forma lentificada, sendo necessária por vezes a repetição da informação (Ichikawa et al., 2017, Cortezzo, Sanders, Brownell, \& Moss, 2015 apud Ichikawa et al., 2017).

Diante da perda neonatal, cumpre-se estabelecer relações de confiança com a equipe de saúde, que precisa unir habilidades com o objetivo de proporcionar um cuidado efetivo no final de vida e no processo de luto desta família. Outrossim, que essas informações sejam compartilhadas de forma hábil, com comunicação clara, objetiva e compassiva, viabilizando à 
família um espaço para contar sua história (Fenstermacher \& Hupcey, 2013 apud Ichikawa et al., 2017).

A perda neonatal envolve múltiplas dimensões, exigindo demandas específicas, inseridas em um contexto familiar e social, além do convívio com diferentes profissionais. Evidencia-se a necessidade de a equipe ser cautelosa em relação ao cuidado com a família, passível de ser abordado por meio da interdisciplinaridade e transdisciplinaridade (Ichikawa et al., 2017). É necessário compreender o cuidado como algo que vai além, que deve ser oferecido de forma integral, embasado em conhecimentos científicos e aceitando as influências da família; um cuidado sem preconceitos e julgamentos, com o objetivo de entender o indivíduo como ser único, completo e complexo.

\section{A atuação da psicologia: técnicas e procedimentos}

Quando se trata de uma perda gestacional, a intervenção do psicólogo precisa estar assentada em uma postura de compreensão e de empatia. Nesse contexto, mensagens sensíveis e claramente preocupadas se fazem importantes como por exemplo "Isto que estão passando deve ser realmente muito difícil", "Estou aqui disponível para vocês" "Fico triste com vocês" "O que posso fazer para vos ajudar?" (Limbo \& Wheeler, 2003; Lothrop, 1997).

O primeiro passo na intervenção clínica frente a uma perda gestacional se inicia na promoção da aceitação da realidade da perda. Desta forma, o psicólogo precisa ajudar o casal ou a pessoa que perdeu o bebê a encarar a perda como de uma pessoa real, que nasceu e morreu, que estava presente e se foi. Assim sendo, é interessante que se dê identidade ao bebê que partiu, autorizando-se a vivenciar o momento de luto; algumas formas de iniciar esse processo é por exemplo, vestido o bebê, permitindo que a família o visite e se despeça, como alguém que já esteve ali um dia, e não como alguém desconhecido. Outras formas de realizar isso é criar recordações do bebê, guardando por exemplo, a pulseira de identificação, ecografias, impressões das suas mãos e/ou pés, roupas e até mesmo fios do cabelo.

É necessário ofertar ao casal a oportunidade de avaliar suas opções, como por exemplo de ver ou não o bebê, independente do que é considerado saudável, ou seja, nenhuma alternativa deve ser imposta aos pais e não se deve insistir na realização ou não do seu funeral. Se faz importante também encontrar pessoas, pais e mães que tenham passado por essa situação para entrar em contato com o casal, com intuito de aumentar sua rede de apoio (Lothrop 1997; Public Health Agency of Canada, 2000). Frente a isso, nos é sabido que nossas crenças não devem intervir nesse momento único dos pais. De acordo com Iaconelli (2007):

\footnotetext{
"Não nos cabe recomendar procedimentos ritualísticos adequados, se desejáveis ou não, pois estes só poderiam sê-lo, partindo da perspectiva do psiquismo dos pais e das possibilidades oferecidas pelo entorno. Para que os pais possam expressar seu desejo há que se evitar constrangimentos e interpelações precipitadas. O tempo sim, é condição que não pode ser desprezada, pois o psiquismo não acompanha a velocidade exigida pela modernidade. No respeito ao desenrolar progressivo do luto, pode-se realizar uma escuta sensível e o que vem ajudar os pais a nomearem sua dor, evitando maiores sofrimentos para si mesmos e para gerações posteriores.” (Iaconelli, 2007, p.621-622)
}

Outra importante ação do psicólogo se refere a facilitar a expressão emocional e a vivência do luto. Nesta fase do processo, é preciso auxiliar os pais a identificar e a expressar as suas emoções, sempre com uma escuta aguçada e empática frente ao que se está passando. Não raramente os pais não entendem que tipos de emoções e manifestações fisiológicas podem aparecer com o luto, por isso, é importante que o psicólogo dê informações acerca das diversas manifestações que podem vir a ocorrer devido às várias fases do processo, além disso pode-se incentivar o compartilhamento da vivência do luto, estimulando assim a capacidade de aceitação frente as diferenças na forma como cada um vivencia a perda. Também é importante mostrar como ser sensível às necessidades do companheiro e na divisão das responsabilidades. (Kavanaugh \& Wheeler, 2003).

Para o final do processo se faz relevante ajudar o casal a ressignificar e integrar a perda e a prosseguir a vida, ensinar quem sofreu a perda a recorrer a técnicas que evitem o foco constante na perda em si, incentivar as relações interpessoais e a 
criação de novos laços com pessoas que estejam dotadas de algumas básicas competências de comunicação assertiva sobre o assunto; o aumento da rede social de apoio do casal pode ser um recurso muito importante nessa fase final do processo. (Rolim \& Canavarro 2001).

Alguns autores como Carvalho e Meyer (2001) constatam uma forte e notória diferença no estado emocional dos pais que recebem apoio familiar e de amigos daqueles que não possuem essa rede de apoio. Normalmente o discurso é de que estão conseguindo reagir minimamente a todo esse sofrimento, pois tem ao lado seus familiares os auxiliando. Bartilotti (2007) fala sobre a necessidade de os pais serem avaliados com cuidado e zelo por diferentes profissionais. Destarte, salienta-se que a assistência psicológica e o atendimento adequados vão ao encontro de facilitar o conhecimento da dinâmica do luto do casal, estando atento às necessidades reais dos mesmos e os auxiliando a enfrentar o processo de forma saudável.

\section{Considerações Finais}

Este trabalho visou dissertar sobre a importância da intervenção psicológica em situações de luto: perinatal e neonatal. A partir da leitura dos artigos, evidenciou-se que a perda na gestação contraria o que culturalmente em nossa sociedade, se espera sobre o andamento do ciclo de vida. Assim, diante de toda repercussão que o luto perinatal pode acarretar para os pais, familiares e até mesmo equipe de saúde, entende-se como fundamental a presença da psicologia.

Nesse sentido, não raras as vezes demonstra-se despreparo por parte das equipes de saúde no que tange os cuidados com a perda, angústia e dor dos pacientes, principalmente pelos seus próprios conflitos relacionados à morte. Os estudos analisados apontam que se atribui ao psicólogo a função de facilitar o contato com o processo de luto, bem como, de possibilitar aos que perderam alguém a chance de expressar seus sentimentos, viabilizando a elaboração do luto pelo filho que se foi.

A intervenção do psicólogo oferece suporte emocional e social, uma vez que ele pode reconhecer o sofrimento diante da perda e fornecer um espaço para o paciente falar sobre essa experiência, o que favorece o processo de elaboração. Dessa forma, considera-se que a instrumentalização de psicólogos para atender a esses casos e avaliar o melhor tipo de intervenção, é importante no trabalho no contexto hospitalar.

Cada mulher tem sua maneira particular de vivenciar um luto deste tipo, o que ressalta a necessidade de o profissional saber respeitar a vivência do sofrimento de cada uma. É importante que ela possa se apropriar da situação e ter consciência do que está passando. A partir daí poderá fazer escolhas, de acordo com seus próprios limites. Esse caráter de sofrimento sensibiliza a quem atende (equipe) e pode tornar difícil a abordagem de temas como a dor e a morte. A partir do que foi estudado, nota-se que é bastante importante que estes aspectos possam ser tratados com clareza e abertura por parte dos profissionais, em especial pelo representante da Psicologia. Outrossim, evidencia-se a necessidade de uma equipe multiprofissional que inclua o psicólogo hospitalar para acompanhar efetivamente as famílias que passaram pela perda perinatal nos serviços de saúde.

Ademais, cabe salientar a importância de estudos futuros que possam investir em novas reflexões acerca do luto perinatal, uma vez que as considerações trazidas por novos estudos podem ter implicações na prática do psicólogo no âmbito hospitalar.

\section{Referências}

Alves, R. S. S., Celestino, K. A. A. (2020). De braços vazios, nos braços da dor: Perda gestacional e neonatal. Research, Society and Development, v. 9, n. $11, \mathrm{e} 5459119804$

Badinter, E. (1985). Um amor conquistado: o mito do amor materno. Rio de Janeiro: Nova Fronteira. 
Research, Society and Development, v. 10, n. 6, e5210615347, 2021

(CC BY 4.0) | ISSN 2525-3409 | DOI: http://dx.doi.org/10.33448/rsd-v10i6.15347

Bartilotti, M. R. M. B. (2007). Intervenção psicológica em luto perinatal. In F. F. Bortoletti (Org.). Psicologia na prática obstétrica: abordagem interdisciplinar. São Paulo: Manole.

Bleichmar, S. (1994). A fundação do inconsciente: destinos de pulsão, destinos de sujeito. Porto Alegre: Artes Médicas.

Carvalho, F. T. \& Meyer, L. (2007). Perda gestacional tardia: aspectos a serem enfrentados por mulheres e conduta profissional frente a essas situações. Boletim de Psicologia, 57 (126), 33-48.

Costa, J. C., \& Lima, R. A. G. (2005). Luto da equipe: revelações dos profissionais de enfermagem sobre o cuidado à criança/adolescente no processo de morte e morrer. São Paulo: Rev. Latino-Am. Enferm.

Chiattone, H. B. C. (2007). Assistência psicológica de urgência. In F. F. Bortoletti, A. F. Moron, J. B. Filho, U. M. Nakamura, R. M. Santana, \& R. Mattar (Eds.), Psicologia na prática obstétrica (pp. 52-60). Barueri: Manole.

Dolto, F. (1984). A gênese do sentimento materno: esclarecimento psicanalítico da função simbólica feminina. In F. Dolto. No jogo do desejo: ensaios clínicos. Rio de Janeiro: Zahar.

Gaíva, M. A. M., Bittencourt, R. M., \& Fujimori, E. (2013) Óbito neonatal precoce e tardio: perfil das mães e dos recém-nascidos. Mato Grosso: Rev Gaúcha Enferm.

Iaconelli, V. (2007). Luto Insólito, desmentido e trauma: clínica psicanalítica com mães de bebês. Revista Latinoamericana de Psicopatologia Fundamental, 10,614-623. http://www.scielo.br/scielo.php?script=sci_isoref\&pid=S1415-47142007000400004\&lng=en\&tlng=pt

Ichikawa, C., Sampaio, P., Sá, N. N., Szylit, R., Santos, S., \& Vargas, D. (2017). O cuidado à família diante da perda neonatal: uma reflexão sob a ótica da Teoria da Complexidade. Pernambuco: Revista de Enfermagem UFPE.

Kübler-Ross, E. (1998). Sobre a morte e o morrer: o que os doentes terminais têm para ensinar a médicos, enfermeiros, religiosos e aos seus próprios parentes. São Paulo: Martins Fontes.

Kavanaugh, K. \& Wheeler, S. R. (2003). When a baby dies: Caring for bereaved families. In C. Kenner, \& J. W. Lott (Eds.)

Lebovici, S. (2004). Diálogo Letícia Solis-Ponton e Serge Lebovici. In L. Solis-Ponton (Org.), Ser pai, ser mãe parentalidade: um desafio para o terceiro milênio. São Paulo: Casa do Psicólogo.pp.

Lemes, P. R. A., Oliveira, E. G. F., Santos, S. P. A., Silva, T. A. R., \& Fitaroni, J. (2018). Luto Materno Perinatal: um estudo a partir da Abordagem Centrada na Pessoa. Mato Grosso: UNIVAG.

Limbo, R. K. \& Wheeler, S. R. (2003). When a baby dies: A handbook for healing and helping. La Crosse: Bereavement Services

Lothrop, H. (1997). Help, comfort, \& hope after losing your baby in pregnancy or the first year. Cambridge, MA: Da Capo Press.

Maldonado, M. (1987). Nós estamos grávidos. Rio de Janeiro: Bloch.

Mercer, V. R. (2002). Volte para casa e desmanche o quartinho: o luto perinatal. In L. M. F. Bernardino, \& C. M. F. Rohenkohl (Eds.), O bebê e a modernidade: abordagens teórico-clínicas (pp. 205-218). São Paulo: Casa do Psicólogo.

Ministério da Saúde - BR (2009). Manual de vigilância do óbito infantil e fetal e do comitê de prevenção do óbito infantil e fetal. Brasília (DF): Ministério da Saúde.

Montero, S. M. P., Sánchez, J. M. R., Montoro, C. H., Crespo, M. L., Jaén, A. G. V., \& Tirado, M. B. R. (2011). A experiência da perda perinatal a partir da perspectiva dos profissionais de saúde. Rev. Latino-Am. Enfermagem.

Muza, J. C., Souza, E. N., Arrais, A. R., \& Iaconelli, V. (2013). Quando a morte visita a maternidade: atenção psicológica durante a perda perinatal. São Paulo: Revista Psicologia: Teoria e Prática

Public Health Agency of Canada (2000). Family-centred maternity and newborn care: National guidelines. Ottawa: Author.

Quintans, E. T. (2018). Eu também perdi meu filho: Luto paterno na perda gestacional/neonatal. Dissertação de mestrado. Pós Graduação PUC-Rio, Rio de Janeiro, BR.

Ripsa - Rede Interagencial De Informação Para A Saúde. (2008). Indicadores básicos para a saúde no Brasil: conceitos e aplicações. 2. ed. Brasília: Organização Pan-Americana da Saúde.

Rolim, L. \& Canavarro, M. C. (2001). Perdas e luto durante a gravidez e o puerpério. In M. C. Canavarro (Ed.). Psicologia da gravidez e da maternidade (pp. 255-297). Coimbra: Quarteto Editora

Soifer, R. (1992). Psicologia da gravidez, parto e puerpério (6ª ed.). Porto Alegre: Artes Médicas.

Turato, E. R. (2003). Tratado da metodologia de pesquisa clínico-qualitativa. Construção teórico-epistemológica, discussão comparada e aplicação nas áreas da saúde e humanas. Petrópolis: Vozes.

Unicef Brasil (2019). Mortalidade Materna e na Infância - Mulheres e crianças estão sobrevivendo cada vez mais. https://www.unicef.org/brazil/comunicados-de-imprensa/mortalidade-materna-e-na-infancia-mulheres-e-criancas-estao-sobrevivendo-cada-vez-mais 